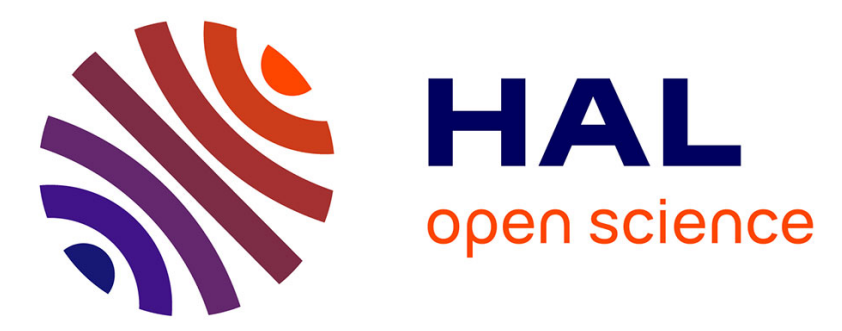

\title{
Impact of Random Body Movements on 60-GHz Doppler Radar for Real-Time Monitoring of Vital Signs
}

Ting Zhang, Guido Valerio, Julien Sarrazin, Dan Istrate

\section{To cite this version:}

Ting Zhang, Guido Valerio, Julien Sarrazin, Dan Istrate. Impact of Random Body Movements on 60-GHz Doppler Radar for Real-Time Monitoring of Vital Signs. 11th International Conference on Body Area Networks, Dec 2016, Turin, Italy. 10.4108/eai.15-12-2016.2267657 . hal-02862326

\section{HAL Id: hal-02862326 \\ https: / hal.sorbonne-universite.fr/hal-02862326}

Submitted on 9 Jun 2020

HAL is a multi-disciplinary open access archive for the deposit and dissemination of scientific research documents, whether they are published or not. The documents may come from teaching and research institutions in France or abroad, or from public or private research centers.
L'archive ouverte pluridisciplinaire HAL, est destinée au dépôt et à la diffusion de documents scientifiques de niveau recherche, publiés ou non, émanant des établissements d'enseignement et de recherche français ou étrangers, des laboratoires publics ou privés. 


\section{Impact of Random Body Movements on $60-\mathrm{GHz}$ Doppler Radar for Real-Time Monitoring of Vital Signs}

\author{
Ting Zhang \\ UPMC Univ Paris 06, UR2, \\ L2E \\ Sorbonne Universités, \\ F-75005 \\ Paris, France \\ ting.zhang@upmc.fr
}

\author{
Guido Valerio \\ UPMC Univ Paris 06, UR2, \\ L2E \\ Sorbonne Universités, \\ F-75005 \\ Paris, France \\ guido.valerio@upmc.fr \\ Dan Istrate \\ CNRS, UMR 7338, \\ Biomechanics and \\ Bioengineering (BMBI) \\ Université de Technologie de \\ Compiègne \\ Compiègne, France \\ mircea-dan.istrate@utc.fr
}

\author{
Julien Sarrazin \\ UPMC Univ Paris 06, UR2, \\ L2E \\ Sorbonne Universités, \\ F-75005 \\ Paris, France \\ julien.sarrazin@upmc.fr
}

\begin{abstract}
We show the impact of random body movements when contactless detection of vital signs is performed with a $60-\mathrm{GHz}$ Doppler radar. Since the monitoring should reveal dangerous events in real-time home-care scenarios, constraints is present on the durations of the observation windows. Body movements of different duration are here considered in connection with such a short-time signal observation.
\end{abstract}

\section{Keywords}

Non-contact vital-sign monitoring, Doppler radar, Optimization algorithm, $60 \mathrm{GHz}$

\section{INTRODUCTION}

Population aging is a major factor motivating the development of home-care services to reduce costs and improve the quality of life of patients [1], and the need for more reliable technical instrumentation for medical monitoring and diagnosis. Specifically, real-time estimation of vital signs is required to detect dangers and act accordingly.

In this framework, the use of continuous wave Doppler radar for non-contact monitoring of vital signs, namely heartbeat $(\mathrm{HB})$ and respiration rates $(\mathrm{RR})$, is a recently established technique. It is based on the detection of the Doppler frequency shift of a wireless signal scattered by the patient. While several applications are envisaged around $5 \mathrm{GHz}$ [2],

Permission to make digital or hard copies of all or part of this work for personal or classroom use is granted without fee provided that copies are not made or distributed for profit or commercial advantage and that copies bear this notice and the full citation on the first page. To copy otherwise, to republish, to post on servers or to redistribute to lists, requires prior specific permission and/or a fee. BODYNETS 2016, December 15-16, Turin, Italy Copyright $\odot 2017$ EAI 978-1-63190-132-4 working at millimeter waves (i.e., around $60 \mathrm{GHz}$ ) provide a more robust estimation of the weaker HB signal [3].

On the other hand, current solutions do not specifically aim at reducing the duration of the observation window. When this duration becomes small (of the order of a few seconds compared with several tens of seconds often used in the existing literature), the estimation is more difficult and dependent on random body movements (RBM), which are not effectively averaged as in the long-duration window.

In this work, RBM of different durations are added to the usual chest movements, and the impact of these movements on the estimation of the vital signs of interest is studied with reference to reasonable accuracies required in this kind of applications.

\section{FORMULATION OF THE PROBLEM}

In CW Doppler radar presented here, a sinusoidal signal (here with frequency $f=60 \mathrm{GHz}$ ) is transmitted towards a person's chest, at an average distance $d_{0}$ (see Fig. 1). The reflected signal is phase-modulated by the signal $x(t)+x_{\mathrm{d}}(t)=$ $x_{\mathrm{h}}(t)+x_{\mathrm{r}}(t)+x_{\mathrm{d}}(t)$, the sum of the heartbeat $x_{\mathrm{h}}(t)$, the breathing $x_{\mathrm{r}}(t)$, and a possible RBM $x_{\mathrm{d}}(t)$. Each vital signal is a simple sinusoid: $x_{\mathrm{h}}(t)=m_{\mathrm{h}} \sin \left(2 \pi f_{\mathrm{h}} t+\phi_{\mathrm{h}}\right)$, and $x_{\mathrm{r}}(t)=m_{\mathrm{r}} \sin \left(2 \pi f_{\mathrm{r}} t+\phi_{\mathrm{r}}\right)$, whose amplitudes $\left(m_{\mathrm{r}}\right.$ and $\left.m_{\mathrm{h}}\right)$, frequencies $\left(f_{\mathrm{r}}\right.$ and $\left.f_{\mathrm{h}}\right)$, and initial phases $\left(\phi_{\mathrm{r}}\right.$ and $\left.\phi_{\mathrm{h}}\right)$ are unknown. The RBM is here a random signal with a prescribed maximum amplitude and time duration. The received signal is demodulated by an IQ quadrature receiver. The two baseband signals $\mathrm{B}_{\mathrm{I}}$ and $\mathrm{B}_{\mathrm{Q}}$ are of the form

$$
B_{\mathrm{I} / \mathrm{Q}}(t)=\sin \left[\frac{\cos }{\sin }\left[\frac{4 \pi x(t)}{\lambda}+\frac{4 \pi x_{\mathrm{d}}(t)}{\lambda}+\frac{4 \pi d_{0}}{\lambda}\right]+n_{\mathrm{I} / \mathrm{Q}}(t),\right.
$$

$\lambda$ being the wavelength at $f . n_{\mathrm{I} / \mathrm{Q}}(t)$ represent the Gaussian noise in the system. A complex demodulation is performed on the received signals, where the final baseband signal is $\mathrm{B}_{\mathrm{C}}(t)=\mathrm{B}_{\mathrm{I}}(t)+j \mathrm{~B}_{\mathrm{Q}}(t)$. 


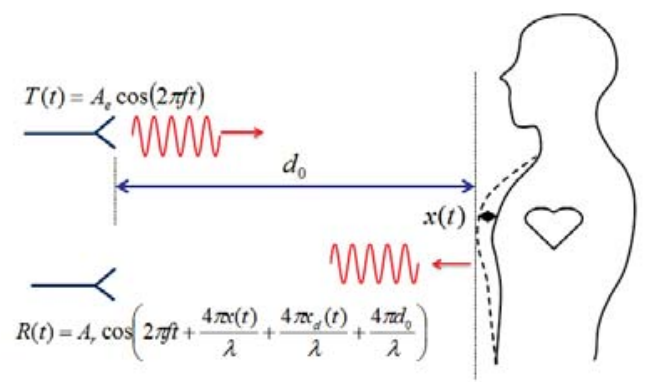

Figure 1: Representation of CW Doppler radar system for vital signs monitoring.

To achieve an accurate frequency estimation, we solve an optimization problem, consisting in finding all unknown parameter in the direct signal model $\mathrm{B}_{\mathrm{C}}(t)$ by minimizing the discrepancy between the measured signal and the estimated one. A particle swarm optimization (PSO), is executed in the time domain, where the signal length and the calculation time is fixed to 5 seconds for real-time capabilities.

\section{NUMERICAL RESULTS}

In this section we show the cumulative distribution functions (CDF) relative to 1000 estimation of the respiration and heartbeat frequencies $f_{\mathrm{r}}$ and $f_{\mathrm{h}}$. For each simulation, amplitudes and frequencies take random values with Gaussian distribution, within realistic ranges, while the phases take uniformly distributed random values. A good estimation of phases grants more robust results for the frequencies, as highlighted by the authors in [4]. The SNR is set here to $20 \mathrm{~dB}$, a typical value in practical systems proposed in the literature. Different RBM are considered, by varying both their maximum amplitudes and time durations.

Figs. 2 shows the CDF in the presence of a RBM of maximum amplitude of $1 \mathrm{~cm}$ ((a) and (b)) and $2 \mathrm{~cm} \mathrm{((c)} \mathrm{and}$ (d)), having different durations. Three cases have been considered: a short movement (1 s), an average movement (2 s), and a long movement $(5 \mathrm{~s})$, where the short and long definitions should be meant with respect to the total observation duration $(5 \mathrm{~s})$. The presence of a RBM does not prevent a reasonably accurate estimation of the frequencies, as long as its duration is not comparable with the observation duration.

In the most critical scenario, the Doppler radar could wait until the patient is again at rest and proceed with a new estimation. Data processing based on the patient medical history should be employed in this limited case in order to conclude about its medical conditions and decide how to proceed (e.g., temporarily using longer observation windows).

\section{CONCLUSIONS}

We have discussed the impact of RBMs on the contactless monitoring of vital signs through Doppler radar at 60 GHz. Real-time applications are specifically targeted, where the observation window is very short and potentially sensitive to irregular movements. However, a good robustness of the proposed estimation technique has been assessed. Data processing algorithms should be employed in the worst-case scenarios where the detection loses precision due to strong and long-lasting movements.

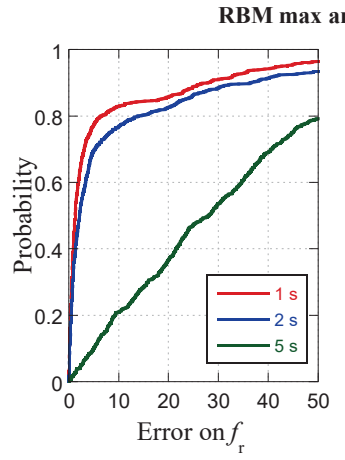

(a)

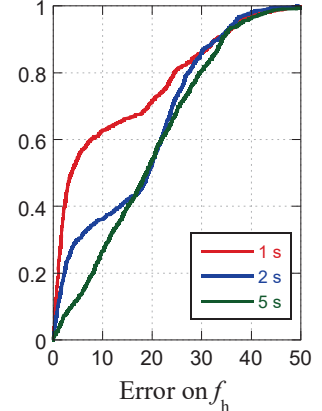

(b)

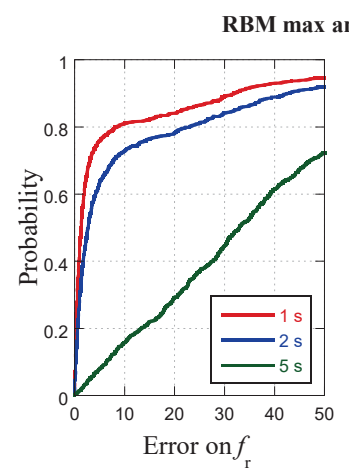

(c)

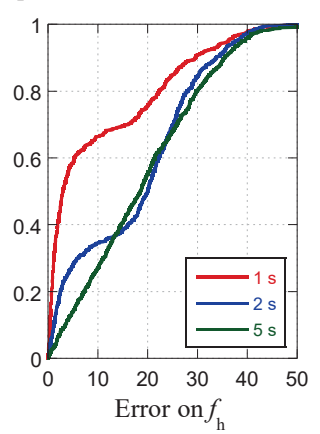

(d)
Figure 2: CDF obtained from the PSO optimization results, related to the frequencies $f_{h}$ and $f_{r}$, in the presence of a RBM. (a) $f_{\mathrm{r}}$ with a RBM of $1 \mathrm{~cm}$; (b) $f_{\mathrm{h}}$ with a RBM of $1 \mathrm{~cm}$; (c) $f_{\mathrm{r}}$ with a RBM of $2 \mathrm{~cm}$; (d) $f_{\mathrm{h}}$ with a RBM of $2 \mathrm{~cm}$.

\section{ACKNOWLEDGMENTS}

The authors would like to thank Sorbonne Universités which has funded the EBiomed Chair and this work. This work was also performed within the Labex SMART supported by French state funds managed by the ANR within the Investissements d'Avenir programme under reference ANR11-IDEX-0004-02

\section{REFERENCES}

[1] P. A. C. Aguilar, J. Boudy, D. Istrate, B. Dorizzi, and J. C. Moura Mota. A Dynamic Evidential Network for Fall Detection. IEEE Journal of Biomedical and Health Informatics, 18(4):1103-1113, JUL 2014.

[2] C. Li and J. Lin. Optimal Carrier Frequency of Non-contact Vital Sign Detectors. In IEEE Radio and Wireless Symp., pages 490-493, Long Beach, CA, Jan. 2007.

[3] T. Zhang, J. Sarrazin, G. Valerio, and D. Istrate. Non-Contact Estimation at $60 \mathrm{GHz}$ for Human Vital Signs Monitoring Using a Robust Optimization Algorithm. In 2016 IEEE Int. Symp. Antennas Prop. , Fajardo, Porto-Rico, June 2016.

[4] T. Zhang, J. Sarrazin, G. Valerio, and D. Istrate. Investigation on non-contact vital signs monitoring using Doppler radar at $5 \mathrm{GHz}$ and $60 \mathrm{GHz}$. IEEE Antennas Wireless Prop. Lett., submitted. 